\title{
Effect of a Wetting Agent and Nitrogen Fertilizer on Establishment of Ryegrass and Mustard on a Burned Watershed
}

\section{LEONARD F. DEBANO AND C. EUGENE CONRAD}

Highlight: $A$ wetting agent was applied by sprinkler irrigation to nitrogen-fertilized plots on a burned watershed in southern California. The wetting agent decreased the total production of mustard (Brassica nigra and $\mathrm{B}$. Campestris) and increased the number of ryegrass seedlings /Lolium rigidum and $\mathrm{L}$. multiflorum/. Where a wetting agent was applied, the moisture conditions at the soil surface were more favorable for seedling establishment and the grass was favored over mustard. In a subsequent laboratory experiment, the wetting agent suppressed mustard seedlings but had a lesser suppressive effect on ryegrass. The differential phytotoxicity was presumably responsible for much of the difference between grass and mustard seedling establishment in the field test. Nitrogen fertilizer increased total plant production and in combination with the wetting agent further enhanced the establishment of ryegrass, but not mustard.

Rates of runoff and erosion during the first winter after fire are high on burned watersheds in southern California. Fire destroys the plant canopy, cxposing the surface soil particles to dislocation by raindrop impact. A water-repellent layer that impedes infiltration, causing overland flow and erosion, can also be formed during fire. Under such conditions, attempts to revegetate may be unsuccessful.

Burned watcrsheds are often seeded with ryegrass (Lolium multiflorum, L. subulatum, or $L$. rigidum) as a means of reducing the severity of erosion. Generally the grass is seeded from September to mid-November. Several months may pass before enough rain falls to germinate the seed. If rainfall is delayed until December or January, low temperatures retard growth of the grass. The rainy season often begins with intense rainstorms. Therefore, considerable erosion is likely even though ryegrass has been seeded.

Wetting agents have been suggested as a remedial treatment to reduce erosion and promote plant growth. These chemicals, when applied properly, increase infiltration into waterrepellent soils. Krammes and Osborn (1969) reported that wetting agents can reduce erosion and runoff by $40 \%$. They must be applied carefully if they are to remain effective. A recent treatment of an entire watershed failed when a wetting agent became ineffective after aging on the soil for over a

The authors are soil scientist and research botanist, Pacific Southwest Forest and Range Experiment Station, Forest Service, U.S. Department of Agriculture, Berkeley, California, stationed at Glendora, Calif.

Manuscript received March 7, 1973. month (Rice and Osborn, 1970).

Plant cover can be increased on burned watersheds by wetting agents. For example, a plot study showed a fourfold increase in annual grass cover when a wetting agent was applied (Osborn et al., 1964). A subsequent laboratory study showed that seeds may not germinate on a water-repellent sand unless a wetting agent is added (Osborn et al., 1967) However, wetting agents can also have a toxic effect on plant growth (Endo ct al., 1969).

In 1970, a forest fire burned a watershed in the West End Soil Conservation District of Cucamonga near Los Angeles. To protect high-value property, district officials decided to try inducing early plant growth by means of sprinkler irrigation and seeding of annual ryegrass ( $L$. rigidum). This treatment afforded us an opportunity to try a wetting agent to remedy water repellency evident in the soil. The wetting agent was applied with the irrigation water through a sprinkler. Several levels of nitrogen were also applied, because nitrogen is considered the nutrient most likely to be deficient on chaparral areas (Hellmers et al., 1955). The field study suggested the possibility of an interaction between ryegrass and mustard (Brassica nigra and B. campestris) treated with the wetting agent. Therefore, we also did a follow-up laboratory study using seedlings of ryegrass ( $L$. multiflorum) and mustard ( $B$. nigra).

This paper reports field trials where a wetting agent was applied by sprinkler to plots fertilized with nitrogen and a subsequent laboratory study undertaken to clarify possible phytotoxic effects observed in the field.

\section{Experimental Design and Methods}

\section{Field Studies}

The study area was at $790 \mathrm{~m}$ elevation on a south-tosouthwest facing slope near the mouth of San Antonio Canyon in the San Gabriel Mountains of southern California. Vegetation prior to burning was a chamise chaparral type composed mainly of chamise (Adenostema fasciculatum) and sage (primarily Salvia millifera). Slopes of the study plots ranged from 65 to $75 \%$. The 8-ha study area and surrounding 16,000 ha had been burned by a wildfire during the summer of 1970 and seeded aerially with ryegrass in the fall. A water-repellent layer was present over most of the area.

On the study area, we laid out 32 plots, each 6 by $10 \mathrm{~m}$. They were established in four blocks of eight plots each, with an upper and a lower tier of four plots in each block. Three levels of ammonium nitrate fertilizer were applied to randomly 
selected plots in the upper and lower tiers. One plot in each tier was not fertilized. Fertilizer levels of 45, 90, and 135 $\mathrm{kg} / \mathrm{ha}$ of nitrogen were broadcast as granulated ammonium nitrate before irrigation was started.

A nonionic wetting agent ${ }^{1}$ was applied to the four lower-tier plots in each block. It was injected into the sprinkler system with a chemical injection pump at a concentration not exceeding $1,650 \mathrm{ppm}$. The application rate was $2431 /$ ha of active ingredient. Our control of the sprinkler irrigation system was limited to insuring that the water was sprayed as uniformly as possible among the experimental plots.

Humidity during the period of irrigation was low. Irrigation was carried on for only 5 days, after which more than $12.7 \mathrm{~cm}$ of rain fell. Although we made no further efforts to evaluate the sprinkler trial, it is unlikely that any ryegrass seed germinated as a result of irrigation.

Gravimetric determinations of soil water and counts of plant density were made during winter. At the end of the growing season in June, vegetation was clipped from a square meter of each plot, and the oven-dry weights of forbs, grass, and shrubs were determined.

\section{Laboratory Study}

The laboratory study was conducted under controlled environmental conditions, where it was set up as a completely randomized factorial experiment with five replicates. The treatments consisted of applying ammonium nitrate fertilizer and wetting agent at the same rates as in the field studies, using ryegrass and mustard planted separately and together.

We used about $180 \mathrm{~g}$ of air-dry water repellent soil in each of 120 aluminum soil cans. Ammonium nitrate was dissolved in distilled water and made up in solutions with concentrations of nitrogen, allowing us to add $10-\mathrm{ml}$ aliquots to each soil can to get the appropriate amount of fertilizer. Similarly, wetting agent was mixed with distilled water and added in 10-ml aliquots to the appropriate soil cans. When the treatment called for omission of fertilizer or wetting agent or both, a 10or 20-ml aliquot of distilled water was added to the soil can. The ryegrass or mustard seeds or both were placed in six spots in each soil can after the first $20 \mathrm{ml}$ of solution was added to the soil surface. In 40 cans (five cans for each of the eight fertilizer-and-wetting-agent combinations), 12 ryegrass seeds were sown. We followed the same procedure when using 12 mustard seeds. Finally, 12 ryegrass and 12 mustard seeds were placed together in the remaining 40 cans. After the seeds were planted, the final $10 \mathrm{ml}$ of distilled water was spread uniformly over the soil surface in each soil can.

Relative humidity in the chamber was maintained at about $65 \%$ during the germination period. The can lids were left loosely in place for 3 days. On the 3 rd day, the lids were removed and seedling condition was evaluated. We observed seedling growth and condition daily for the next 12 days. During the first 7 days, the soil surface was kept moist by adding distilled water. During this period, about $30 \mathrm{ml}$ of water was added to the cans and about $20 \mathrm{ml}$ was lost, mainly by evaporation from the soil surface. We lowered the relative humidity in the chamber to about $40 \%$ from $65 \%$ after the 7 th day to assess the ability of the seedlings to withstand increased moisture stress. The soil was allowed to dry to approximately $3 \%$ on an air-dry basis before additional water was provided

\section{Results and Discussion}

\section{Water Penetration and Erosion}

Soil water was sampled on December 4, 1970, after 17.3

\footnotetext{
${ }^{1}$ The wetting agent used is sold under the commercial name of "Water In." The active ingredient is ALKYL polyethylene glycol ether. Trade names and commercial products are mentioned solely for necessary information. No endorsement by the U.S. Department of Agriculture is implied.
}

Table 1. Average soil water content $(\%)$ at three soil depths on plots treated with a wetting agent and on untreated control plots

\begin{tabular}{lccc}
\hline \hline & \multicolumn{3}{c}{ Soil depth $(\mathrm{cm})$} \\
\cline { 2 - 4 } Item & $0-1$ & $1-3$ & $3-8$ \\
\hline Treated plots & 21.7 & 18.0 & 17.8 \\
Untreated plots & 10.4 & 13.4 & 15.5 \\
Difference & $11.3^{1}$ & 4.6 & 2.3 \\
\hline
\end{tabular}

${ }^{1}$ Statistically significant at the $1 \%$ probability level.

$\mathrm{cm}$ of rain had fallen. This rain started germination. On December 15, 1970, soil was again sampled, and the total rainfall by then was $19.3 \mathrm{~cm}$. We combined data for both dates, because the gravimetric water content of any particular layer on December 4, 1970, was not statistically different from that of the same layer 11 days later (Table 1). Furthermore, differences between the fertilizer treatments on either date were not significant, so the data were summarized only by wetting agent and soil depth. The water content of the 0 - to $1-\mathrm{cm}$ layers in the plots treated with wetting agent differed significantly from that in the untreated plots at the $1 \%$ probability level. Apparently, wetting agent allowed water to wet the formerly water-repellent $0-$ to $1-\mathrm{cm}$ layer. Water content of the 1- to 3-and 3- to 8-cm soil depths did not differ statistically between the treated and untreated plots even though infiltration was better on the treated plots (Table 1).

The soil surface was drier on the untreated plots for at least two reasons. First, less water was probably absorbed during the rain because of the water-repellent layer. Second, water repellency also restricted capillary movement of water to the surface and allowed it to dry out (DeBano et al, 1967).

We did not measure erosion, but we observed moderate rilling in the untreated areas and virtually none in the treated areas. Improved infiltration was the most likely reason for reduced erosion on the treated plots.

\section{Germination and Establishment of Plants}

The wetting agent trcatment favored the establishment of ryegrass and discouraged the establishment of mustard. Most seedlings of ryegrass and mustard in the treated plots were established quickly after the first rainstorm, whereas in the untreated plots establishment of grass and forb seedlings was distributed over a longer period of time (Table 2). This difference suggests that the treatment resulted in a more moist soil surface (Table 1) and enhanced germination. The surface $1-\mathrm{cm}$ layer on the treated plots had an average water content of $21.7 \%$ compared to $10.4 \%$ on the untreated plots. The amount of additional water retained in the upper $8 \mathrm{~cm}$ on the treated soil was about $40,0001 /$ ha.

At first, we concluded that the different response of ryegrass and mustard was an allelopathic effect produced by

Table 2. Plant density (plants $/ \mathrm{m}^{2}$ ) on plots treated with a wetting agent and on untreated plots, on two sampling dates.

\begin{tabular}{lccc}
\hline $\begin{array}{l}\text { Species and } \\
\text { treatment }\end{array}$ & $\begin{array}{c}\text { Dec. 15, } \\
1970\end{array}$ & $\begin{array}{c}\text { Jan. 19, } \\
1971\end{array}$ & $\begin{array}{c}\% \\
\text { Change }\end{array}$ \\
\hline Ryegrass & & & \\
$\quad$ Untreated plot & 46 & 60 & 30 \\
$\quad$ Treated plot & 77 & 75 & -2 \\
Mustard & & & \\
$\quad$ Untreated plot & 30 & 82 & 173 \\
Treated plot & 20 & 25 & 25 \\
\hline
\end{tabular}


the ryegrass. In a subsequent laboratory test, however, the wetting agent suppressed germination of both species, but to a greater degree in the mustard than in the ryegrass.

We found no indication that the level of nitrogen fertilizer applied affected the density of ryegrass and mustard.

\section{Plant Production}

The effect of wetting agent on germination and establishment of herbaceous plants was reflected in plant production at the end of the growing season. The incrcases in total plant and grass production on plots treated with wetting agent were statistically significant (Fig. 1). The wetting agent almost doubled the growth of ryegrass while retarding production by mustard.

Total plant production on the untrcated plots increased with higher rates of nitrogen fertilization, but the increase was not statistically significant because replicates varied greatly. Nitrogen applied to the plots treated with wetting agent increased total plant production only slightly, although the proportion of ryegrass and mustard at different levels of fertilizer showed marked changes. The wetting agent apparently increases productivity on the site, and the differing levels of fertilizer merely redistribute the productivity between ryegrass and mustard. The differential response of ryegrass and mustard was not observed on the untreated plots, where both mustard and ryegrass increased slightly with increasing nitrogen.

\section{Laboratory Germination}

Most ryegrass and mustard seeds in the laboratory study germinated, but there was an early and conspicuous difference between the seedlings developing from seeds in treated and untreated cans. Three days after seeding, only primary roots were visible on the mustard and ryegrass seeds treated with wetting agent. In contrast, untreated mustard and ryegrass not only had primary roots, but also had developed cotyledons up to $1 \mathrm{~cm}$ long. By then, the primary roots of the treated mustard had shown a peculiar geotropic response as well as excessive fine hair development on the roots. Instead of penetrating the soil, the primary roots grew along the surface of the soil in a more or less flat spiral fashion, and some roots tended to turn upward away from the soil surface. These phenomena were not observed in the roots developing from ryegrass or untreated mustard seeds.

Germination and seedling establishment were completed within 5 days after planting the seeds (Table 3). No change in number of plants was noted between then and the 7 th day. When the two species were seeded in separate cans, there were significantly more plants in the untreated soil cans seeded to

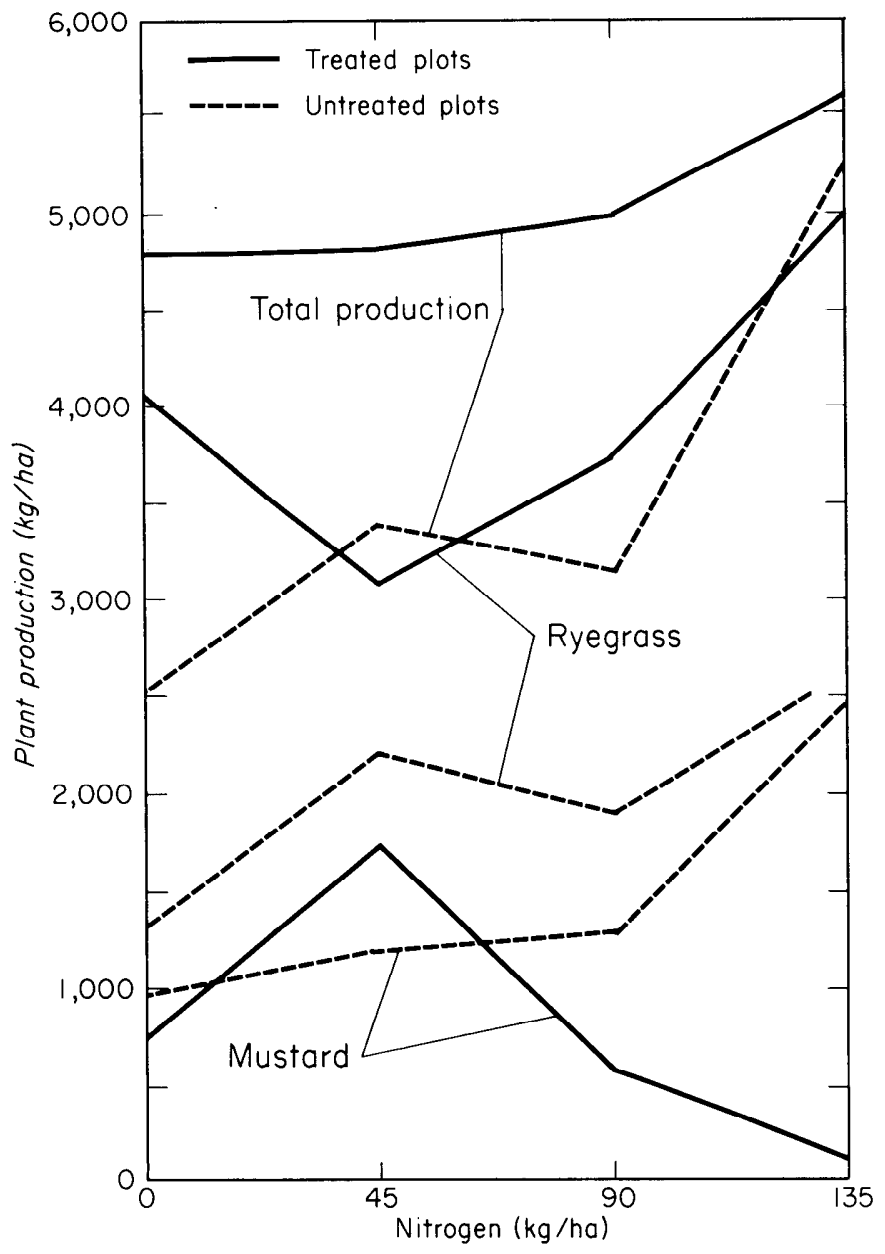

Fig. 1. Plant production in response to fertilizer applications on plots treated with a wetting agent compared with untreated plots. Vegetation was measured at the end of the growing season, and totals include shrubs on some plots.

mustard than in the other treatment combinations. However, when the two species were mixed, there were significantly more seedlings of both ryegrass and mustard in the treatment, excluding the wctting agent.

The wetting agent also had a significant effect on the number of plants which grew at least $1 \mathrm{~cm}$ tall (Table 3). Seventy-nine percent of all germinated seedlings in the untreated soil cans were at least $1 \mathrm{~cm}$ tall after 5 days. After 7 days, $98 \%$ of the ryegrass and $85 \%$ of the mustard seedlings were $1 \mathrm{~cm}$ or more tall. In contrast, in the treated soil only

Table 3. Germination and growth of ryegrass and mustard seedlings in cans of soil treated with wetting agent.

\begin{tabular}{|c|c|c|c|c|c|c|}
\hline \multirow[b]{3}{*}{ Planting method } & \multirow{2}{*}{\multicolumn{2}{|c|}{$\begin{array}{l}\text { Average plants per can } \\
\text { after } 5 \text { days }{ }^{1}\end{array}$}} & \multicolumn{4}{|c|}{ Average plants per can more than $1 \mathrm{~cm}$ tall } \\
\hline & & & \multicolumn{2}{|c|}{ After 5 days } & \multicolumn{2}{|c|}{ After 7 days } \\
\hline & Treated & Untreated & Treated & Untreated & Treated & Untreated \\
\hline \multicolumn{7}{|l|}{ Separate planting ${ }^{3}$} \\
\hline Ryegrass & $10.3 \mathrm{a}^{2}$ & $10.6 \mathrm{a}$ & $4.6 \mathrm{~b}$ & $8.0 \mathrm{c}$ & $9.2 \mathrm{~b}$ & $10.2 \mathrm{~b}$ \\
\hline Mustard & $10.2 \mathrm{a}$ & $11.6 \mathrm{~b}$ & $1.3 \mathrm{a}$ & $9.1 \mathrm{c}$ & $2.4 \mathrm{a}$ & $10.1 \mathrm{~b}$ \\
\hline \multicolumn{7}{|l|}{ Mixed planting ${ }^{3}$} \\
\hline Ryegrass & $8.4 \mathrm{a}$ & $10.2 \mathrm{~b}$ & $3.8 \mathrm{~b}$ & $8.4 \mathrm{c}$ & $7.6 \mathrm{~b}$ & $10.2 \mathrm{~d}$ \\
\hline Mustard & $9.0 \mathrm{a}$ & $10.8 \mathrm{~b}$ & $2.0 \mathrm{a}$ & $8.5 \mathrm{c}$ & $3.6 \mathrm{a}$ & $9.0 \mathrm{c}$ \\
\hline
\end{tabular}

\footnotetext{
${ }^{1}$ Includes all plants regardless of height.

${ }^{2}$ Within each block of 4 means, any values not followed by the same letter differ significantly at the $5 \%$ level of probability.

${ }^{3}$ Planted 12 seeds per soil can per species; 24 seeds total per can in mixed planting.
} 
$45 \%$ of the ryegrass and $17 \%$ of the mustard seedlings were 1 $\mathrm{cm}$ tall after 5 days. Ninety percent of the ryegrass and $31 \%$ of the mustard seedlings were at least $1 \mathrm{~cm}$ tall after 7 days in the treated soil cans. Growth of both ryegrass and mustard was slow in the treated soil, but ryegrass recovered from the effect of wetting agent more rapidly than did mustard.

The seedlings were watered on the 7 th day and then subjected to water stress by lowering the relative humidity from 65 to $40 \%$. After 6 days evaporation and transpiration lowered the soil water from 25 to $3 \%$. The reaction of the plants to water stress did not differ between the soil receiving a wetting agent treatment and the untreated controls. The plants in both treated and untreated soil recovered equally well when they were watered again and the humidity was raised back to $65 \%$.

Nitrogen fertilization adversely affected germination and seedling growth in the laboratory experiment. In the separate plantings, the total numbers of ryegrass and mustard plants were significantly less in the fertilized soil cans than in the unfertilized. Wetting agent and fertilizer levels did not interact significantly when the ryegrass and mustard plants were planted separately. When the two species were planted in mixed plantings, there were significantly fewer plants taller than $1 \mathrm{~cm}$ in the fertilized pots. The interaction between wetting agent and fertilizer was also significant in contrast with the separate plantings.

There were no significant interactions between species and fertilizer or between species and wetting agent. In both the mixed and separate plantings, the species differed significantly, but this difference was attributed primarily to the presence of the wetting agent rather than to differences in phytotoxicity between the plant species or soil treatment and plant species.

\section{Conclusions}

The results of these experiments have useful implications concerning germination and early establishment of seedlings under field conditions. For example, we observed that when fertilizers and wetting agents are applied in field trials, ryegrass often becomes the predominant plant in the treated areas. The differential response of ryegrass and mustard may partly explain the dominance of a site by ryegrass. Probably, other plant species are also strongly affected by a wetting agent. Consequently, species sensitivity could easily produce changes in the composition of the plant community. Under certain circumstances these changes may be desirable, whereas in other situations they may not be.

\section{Literature Cited}

DeBano, L. F., J. F. Osborn, J. S. Krammes, and J. Letey, Jr. 1967. Soil wettability and wetting agents ... our current knowledge of the problem. USDA Forest Serv. Res. Paper PSW-43. Pacific Southwest Forest \& Range Exp. Sta., Berkeley, Calif.

Endo, R. M., J. Letey, N. Valoras, and J. F. Osborn. 1969. Effects of nonionic surfactants on monocots. Agron. J. 61:850-854.

Hellmers, H., J. F. Bonner, and J. M. Kelleher. 1955. Soil fertility: watershed management problem in the San Gabriel Mountains of southern California. Soil Sci. 80:189-197.

Krammes, J. S., and J. Osborn. 1969. Water-repellent soils and wetting agents as factors influencing erosion. In: L. F. DeBano and J. Letey (ed). Proc. Symp. Water-Repellent Soils. Univ. of Calif., Riverside, Calif. p. 177-187.

Osborn, J. F., R. E. Pelishek, J. S. Krammes, and J. Letey. 1964. Soil wettability as a factor in erodibility. Soil Sci. Soc. Amer. Proc. 28:294-295.

Osborn, J., J. Letey, L. F. DeBano, and E. Terry. 1967. Seed germination and establishment as affected by non-wettable soils and wetting agent. Ecology 48:494-497.

Rice, R. M., and J. F. Osborn. 1970. Wetting agent fails to curb erosion from burned watershed. U. S. Dep. Agr. Forest Serv., Pacific Southwest Forest \& Range Exp. Sta., Berkeley, Calif. USDA Forest Service Res. Note PSW-219.
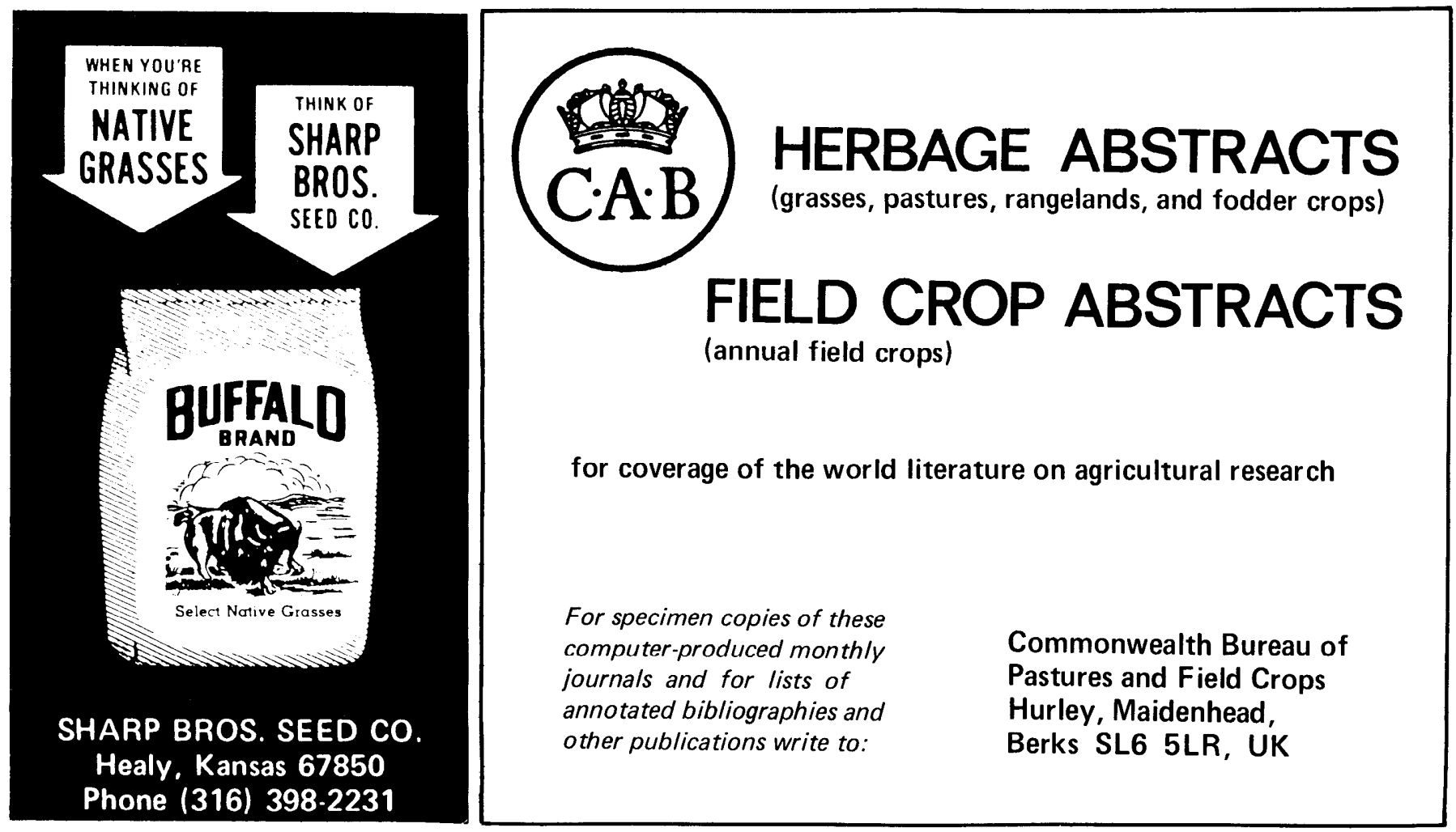